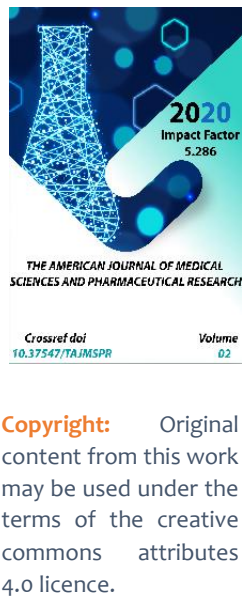

\title{
Medical Problems In Patients With Alcohol Dependence With Common Schizophrenia And Schizoaffective Disorder
}

\author{
S.Sh. Karimova \\ Bukhara Medical Institute, Uzbekistan \\ Yu.Y. Ergasheva \\ Bukhara Medical Institute, Uzbekistan
}

\section{ABSTRACT}

Goal of this study of the relationship between alcohol use, severity of psychiatric symptoms and the number of verified medical diagnoses. The study was that self-reporting of medical history is less accurate in patients with comorbid alcohol dependence and schizophrenia compared with patients with alcohol dependence only or with control. 46 patients with schizophrenia or schizoaffective disorder and concomitant alcohol dependence recruited from the Bukhara Regional Psychoneurological Dispensary. 27 patients suffered from schizophrenia, and 19 patients from schizoaffective disorder.

\section{KEYWORDS}

Alcohol addiction, medical problems, schizophrenia, schizoaffective psychosis

\section{INTRODUCTION}

Excessive alcohol consumption affects many body systems, including the nervous, gastrointestinal, hematopoietic, cardiovascular, and endocrine systems. Schizophrenia and alcohol use disorders are independent major risk factors for various medical problems. Patients with schizophrenia and associated foam have a higher morbidity than patients with schizophrenia alone $[1,2]$. Most often, schizophrenia precedes alcoholism, although another sequence in the development of these two diseases is possible 
[2]. Medical conditions can go unrecognized and poorly understood, placing this group of patients at higher risk.

These patients may neglect general health care $[1,4]$ because of barriers between mental health and general health services, stigma, cognitive problems associated with both substance use and schizophrenia, and adherence problems $[2,4]$. A study of medical problems with schizophrenia or schizoaffective disorder and concomitant alcohol dependence was carried out in 46 patients.

Goal of this study of the relationship between alcohol use, severity of psychiatric symptoms and the number of verified medical diagnoses. The study was that self-reporting of medical history is less accurate in patients with comorbid alcohol dependence and schizophrenia compared with patients with alcohol dependence only or with control.

\section{RESEARCH METHODS}

46 patients with schizophrenia or schizoaffective disorder and concomitant alcohol dependence recruited from the Bukhara Regional Psychoneurological Dispensary. 27 patients suffered from schizophrenia, and 19 patients from schizoaffective disorder.

All patients underwent a detailed structured history, physical examination and review of all available medical records. Self-proclaimed medical problems were documented and compared with problems obtained from medical records (outpatient records, hospital discharge summaries, and emergency department visit records). Baseline demographic data included age, gender, race, educational attainment, and employment status.

Alcohol and substance use as well as diagnoses were assessed using a structured clinical interview for DSM-IV [SCID]. Symptoms of schizophrenia were assessed on the Positive and Negative Syndrome Scale [PANSS]. The diagnosis of schizophrenia versus schizoaffective disorder was assessed using SCID. The severity of depression was assessed using the Calgary Depression Scale for Schizophrenia [CDSS] in patients with schizophrenia or schizoaffective disorder. Spearman's RO coefficient was carried out using data from 46 subjects to assess the relationship between self-report accuracy and the following indicators:

1. Demographic variables: age, gender, years of schooling and employment status

2. Alcohol and other substance use variables: number of days drunk, month, number of standard drinks per week, number of cigarettes, week

3. Variables describing the severity of psychiatric symptoms: positive, negative and overall PANSS scores, PANSS composite score [positive minus negative scale score] Calgary Depression Scale for Schizophrenia

4. The total number of verified medical diagnoses

\section{RESEARCH RESULTS AND DISCUSSION}

Demographic data, the number of verified and registered medical diagnoses, the severity of psychiatric symptoms, alcohol and psychoactive substance use are summarized in Table 1. The majority of patients with schizophrenia, schizoaffective disorder and 
The American Journal of Medical Sciences and Pharmaceutical Research

(ISSN - 2689-1026)

Published: December 31, 2020 | Pages: 97-102

alcohol dependence were middle-aged, male, and disabled. Control patients included a lower proportion of women.

Table 1

Socio-demographic and clinical characteristics

\begin{tabular}{|c|c|c|c|c|c|}
\hline & $\begin{array}{l}\text { Control } \\
\qquad \mathrm{N}=8\end{array}$ & $\begin{array}{c}\text { Alcohol } \\
\text { dependence } \\
\mathrm{N}=47\end{array}$ & $\begin{array}{l}\text { Schizophrenia } \\
\qquad \begin{array}{l}\mathrm{N}=\mathbf{2 7}\end{array}\end{array}$ & $\begin{array}{l}\text { Schizoaffective } \\
\qquad N=19\end{array}$ & $\begin{array}{l}\text { Kruskal- } \\
\text { Wallis } \\
\text { ANOVA }\end{array}$ \\
\hline Age [years] & $33 \pm 13$ & $40 \pm 13$ & $42 \pm 7$ & $31 \pm 7$ & NS \\
\hline 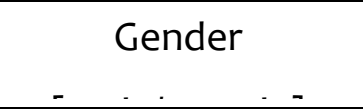 & $3 / 5$ & $2 / 8$ & $25 / 2$ & $12 / 6$ & 0.011 \\
\hline Marital status & $7 / 0 / 0 / 1$ & $12 / 16 / 12 / 6$ & $10 / 9 / 3 / 5$ & $8 / 5 / 3 / 3$ & NS \\
\hline Employment [Yes / & $2 / 6$ & $5 / 41$ & $2 / 25$ & $7 / 12$ & $<0.001$ \\
\hline No, not & $0.1 \pm 0.2$ & $2 \pm 23^{*}$ & $17 \pm 10^{*}$ & $8 \pm 11^{*}$ & $<0.001$ \\
\hline $\begin{array}{l}\text { No, not } \\
. . \quad \ldots .\end{array}$ & $0 \pm 0$ & $0 \pm 7^{*}$ & $7 \pm 3^{*}$ & $7 \pm 6^{*}$ & $<0.001$ \\
\hline calgary Depression & $N / A$ & $\mathrm{~N} / \mathrm{A}$ & $3 \cdot 3 \pm 3 \cdot 4$ & $6.9 \pm 3.2$ & $<0.001$ \\
\hline Positive PANSS & $\mathrm{N} / \mathrm{A}$ & $N / A$ & $12.1 \pm 4 \cdot 4$ & $15.0 \pm 6.1$ & NS \\
\hline Negative rating of & $\mathrm{N} / \mathrm{A}$ & $\mathrm{N} / \mathrm{A}$ & $14 \cdot 9 \pm 4 \cdot 9$ & $10.7 \pm 2.7$ & 0.002 \\
\hline Overall rating & $\mathrm{N} / \mathrm{A}$ & $\mathrm{N} / \mathrm{A}$ & $21.5 \pm 4.0$ & $12.9 \pm 6.6$ & NS \\
\hline PANSS composite & $\mathrm{N} / \mathrm{A}$ & $\mathrm{N} / \mathrm{A}$ & $-1.2 \pm 7.6$ & $3.9 \pm 5.6$ & 0.001 \\
\hline
\end{tabular}

Patients with alcohol dependence drank significantly more than controlpatients and patients with schizophrenia. Schizoaffective patients drank significantly morethan patients with schizophrenia. There was no significant difference in the severity of alcohol use between schizoaffective and schizophrenic 
patients. Patients with schizoaffective disorder and schizophrenia had significantly more verified medical problems [ an average of 2.7] compared to controls, patients with schizophrenia, and patients with alcohol dependence only .

Subjects with alcoholdependence, schizophrenia, or schizoaffective disorder недооцени problems. The number of self-reported medical problems was significantly lower than the actual verified numberof diagnoses in subjects with schizophrenia [тест Wilcoxon test $\mathrm{P}=0.001]$ schizoaffective disorder/BA [Wilcoxon test POn the contrary, control subjects accurately reported almost all of them [89\% about their medical problems.

The results of associative analysis are summarized in table 2 .

Correlation analysis between underreporting of medical diagnoses and demographics, alcoholism severity, and psychiatric severity.

\begin{tabular}{|c|c|c|c|c|}
\hline & Control & $\begin{array}{l}\text { Alcohol } \\
\text { dependence }\lceil A D\rceil\end{array}$ & Schizophrenia & SchizoaffectiveSchizoaffective \\
\hline $\mathbf{N}$ & 8 & 46 & 27 & 19 \\
\hline Age [Years] & $\begin{array}{l}0.210 \\
\lceil N S 1\end{array}$ & $0.202[N S]$ & $0.070[\mathrm{NS}]$ & $0.101[N S]$ \\
\hline Gender [Male/Female] & $\begin{array}{l}0.327 \\
{[N S 1}\end{array}$ & $0.086[N S]$ & $-0.247[N S]$ & $0.248[N S]$ \\
\hline Education [years] & $\begin{array}{l}0.263 \\
\lceil N S\rceil\end{array}$ & $0.098[N S]$ & $0.168[N S]$ & $0.075[\mathrm{NS}]$ \\
\hline Employment [Yes / no] & $\begin{array}{l}0.189 \\
\lceil N S\rceil\end{array}$ & $-0.121[N S]$ & $-0.072[N S]$ & $-0.064[N S]$ \\
\hline $\begin{array}{l}\text { Number of verified medical } \\
\text { diagnoses }\end{array}$ & $\begin{array}{l}0.348 \\
{[N S 1}\end{array}$ & $0.448[0.003]$ & $\begin{array}{l}0.609 \\
\lceil<0.001\rceil \\
\end{array}$ & $0.655[<0.001]$ \\
\hline $\begin{array}{l}\text { Number of days / month } \\
\text { consumed }\end{array}$ & $\mathrm{N} / \mathrm{A}$ & $0.032[\mathrm{NS}]$ & $-0.039[\mathrm{NS}]$ & $0,131[N S]$ \\
\hline $\begin{array}{l}\text { Number of standard drinks } \\
\text { per week }\end{array}$ & $\mathrm{N} / \mathrm{A}$ & $-0.176[N S]$ & $-0.020[N S]$ & $0.172[N S]$ \\
\hline Positive PANSS rating & $\mathrm{N} / \mathrm{A}$ & $\mathrm{N} / \mathrm{A}$ & $-0.028[N S]$ & $-0.063[N S]$ \\
\hline Negative rating PANSS & $\mathrm{N} / \mathrm{A}$ & $\mathrm{N} / \mathrm{A}$ & $-0.058[N S]$ & $-0.081[N S]$ \\
\hline Overall rating PANSS & $\mathrm{N} / \mathrm{A}$ & $\mathrm{N} / \mathrm{A}$ & $-0.174[N S]$ & $0.002[\mathrm{NS}]$ \\
\hline PANSS composite index & $\mathrm{N} / \mathrm{A}$ & $\mathrm{N} / \mathrm{A}$ & $0.012[\mathrm{NS}]$ & $-0.039[N S]$ \\
\hline
\end{tabular}




\begin{tabular}{|l|l|l|l|l|}
\hline & Control & $\begin{array}{l}\text { Alcohol } \\
\text { dependence [AD1 }\end{array}$ & Schizophrenia & SchizoaffectiveSchizoaffective \\
\hline calgary Depression Score & N/A & N/A & $-0.243[0.022]$ & 0.038 [NS] \\
\hline
\end{tabular}

The most commonly underreported medical diagnosis ofAMI in patients with schizophrenia and schizoaffective disorder would bewhether the coronary heart disease [ 2 from $1,100 \%$ not reported], chronic renal failure [2 of $2100 \%$ not reported], gastroesofageoLina reflux disease [4 11, 29\% ne was reported], hyperlipidemia [3 of $8,22 \%$ were not reported], asthma [2 17, $14 \%$ not reported] and hypertension [4 35, 12\% not reported]

\section{DISCUSSION}

The aim of this study was to study the problems in patients with schizophrenia or schizoaffective disorder and concomitant alcohol dependence compared to patients with only alcoholdependence and control. In contrast to the previously reported high accuracy of self-reporting of drug and alcohol use in research settings, self-reporting of medical problems had limitedaccuracy only in patients with alcohol dependence and was significantly less accurate in patientswith concomitant schizophrenia and schizoaffective disorder. While patients withconcomitant schizophrenic spectrum disorders were more inaccurate in reporting medical problems, the accuracy of self-reporting did not significantly correlate with rates of alcohol use and severity of psychosis, but negatively correlated with the numberof medical diagnoses. The absence of a significant correlation between the accuracy of self-reporting and the selected indicators of severity of psychosis and substance use in this small cohort does not exclude the potential impact of severity of psychosis and substance use on accuracy.

Theresults of this study are that medical problems and disorders associated with substance use have been carefully assessed using various methods: physical examination, laboratory tests, self-reporting, diagnostic interviews, and a comprehensive review of medical records. Doctors are often unaware of the many chronic diseases that are present in patients with schizophrenic spectrum disorders andalcohol dependence.

\section{CONCLUSIONS}

Our results show that a combination of these disorders is associated with less accurate reporting of medical problems than controls and evenalcohol-dependent patients alone. In the treatment of patients with schizophrenic spectrum disorders and concomitant alcohol dependence, we recommend a physical examination and careful analysis ofexisting medical records in the CEC. Using targeted screening forms that include questions about common medical conditions found in this пациентыаrea can help improve the health care of these vulnerable patients.

\section{REFERENCES}

1. Addington D, Addington J, MatikaTyndale E. assessing depression in schizophrenia: the calgary depression 


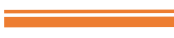

Scale. $\quad \mathrm{Br} \quad J \quad$ Psychiatry Suppl.1993;[22]:39-44.

2. Koshkina E. A. Epidemiology of drugrelated diseases. Guide to narcology. "M...":MedpraktikaPubl., 2002, Vol. 1, Pp. 8-32

3. Strelets N. V. Clinic and treatment of poly-drug addiction . Lectures on narcology / ed. N. N. Of iwaniec. - M.: MedpractikaPubl., 2001, Pp. 214-222

4. Rokhlina M. L., Mokhnachev S. O. Mental and behavioral disorders associated with the combined use of drugs and other psychoactive substances. Narcology: a national guide / ed. N. N. Ivants, I. P. Anokhina, and M. A. Vinnikova, Moscow: GEOTAR-Media, 2008, Pp. 320-323

5. Batki SL, Dimmock JA, Ploutz-Snyder R, Meszaros ZS, Canfield K. directly controlled naltrexone reduces heavy drinking in schizophrenia: a preliminary analysis of a controlled study. Alc Clin Exp Res Suppl. 2009;33[6]: 116A.]

6. Batki SL, Meszaros ZS, Strutynski K, Dimmock JA, Leontieva L, PloutzSnyder R, Canfield K, Drayer R. medical comorbidity in patients with schizophrenia and alcohol dependence. Schizophr Res. 2009;107[2-3]: 139-146.

7. Capasso RM, Lineberry TW, Bostwick JM, Decker PA, St Sauver J. mortality in schizophrenia and schizoaffective disorder: the County cohortOlmsted, Minnesota: 1950-2005. Schizophr Res. 2008;98[1-3]: 287-294.

8. Carney CP, Jones L, Woolson RF. Medical comorbidity in women and men with schizophrenia: a populationbased controlled study. J Gen Intern Med. 2006;21[11]:1133-1137.
9. Colton CW, Manderscheid RW. Coincidences in rates of increased mortality, lost years of potential life, and causes of death among government mental health clients in eight States. Prev Chron Dis. 2006;3[2]: A42

10. De Alba I, Samet JH, Saitz R. burden of medical diseases in drug-and alcoholdependent individuals without primary health care. I'm An Addict. 2004;13[1]:33-45

11. Dennis ML, Funk R, Godley SH, Godley $M D$, Waldron $H$. cross validation of measures for alcohol and cannabis use in the global individual needs assessment [GAIN] and time feedback [TLFB; form 90] among adolescents receiving treatment психоактивнымиfor substanceabuse. Dependence. 2004;99[2]:120-128.

12. Dickey B, Normand SL, Weiss RD, Drake RE, Azeni H. medical morbidity, mental illness and substance use disorders. PsychiatristServ. 2002; 53[7]:861-867 